\title{
Uma Visão Crítica do Uso de Padrões de Exposição na Vigilância da Saúde no Trabalho
}

\section{A Critical View of the Use of Exposure Standards in Occupational Health Surveillance}

\author{
Fernando D. Vasconcelos ${ }^{1}$
}

\section{VASCONCELOS, F. D. A Critical View on Exposure Standards of Medical Surveillance in} Occupational Health. Cad. Saúde Públ., Rio de Janeiro, 11 (4): 588-599, Oct/Dec, 1995.

The reductionist application of the concepts of cause and standard in Occupational Medicine is studied by examining human exposure limits for chemical agents in industry. The author discusses several scientifc and technical shortcomings in such exposure standards, including those used in Brazil, and analyzes their use as a way to classify as normal some risk factors in the workplace.

Key words: Occupational Medicine; Occupational Exposure; Chemical Agents; Threshold Limit Value; Health Surveillance

\section{INTRODUÇÃO}

\section{Causa e Norma na Medicina do Trabalho}

Embora, há mais de trezentos anos, Ramazzini (1988), considerado o pai da Medicina do Trabalho, abordasse de forma abrangente o agravo à saúde pelo trabalho, tendo em conta múltiplos determinantes, esse ramo da prática médica só veio estruturar-se no século XIX, época de hegemonia do unicausalismo, no qual firmou suas raízes.

Naquele período, ocorria o processo de redefinição da prática médica como prática social. Era época de movimentos sociais revolucionários em toda Europa, do advento da indústria e ascensão da burguesia ao poder. $\mathrm{O}$ novo Estado precisava, então, fortalecer-se perante a nação em formação e atenuar as tensões na sociedade. As péssimas condições de trabalho nas fábricas e a utilização de uma mão-de-obra constituída principalmente por mulheres e crianças, submetidas a jornadas de mais de dezesseis horas diárias, geravam altos

\footnotetext{
${ }^{1}$ Inctituto de Saúde Coletiva, Universidade Federal da Bahia: Rua Padre Feijó, 29 - 4⿳o andar, Salvador, BA, 40110-170, Brasil.
}

índices de morbi-mortalidade relacionados ao trabalho (Engels, 1985). A deterioração gradativa da saúde dos operários levava a reivindicações por medidas de prevenção de agravos e assistência médica. A introdução de médicos nas fábricas passou a ser vista pelos patrões como necessária ao desenvolvimento do próprio processo produtivo e ao amortecimento de conflitos inerentes ao modo de produção capitalista.

Inicialmente, a Medicina do Trabalho não estabeleceu claramente um objeto de estudo próprio. Mendes (1980) considera que, nesse período inicial, a atribuição do médico do trabalho era semelhante à de um clínico que atuava dentro da fábrica. Não se deve obscurecer, entretanto, que, naquela circunstância, o papel do médico na reprodução da força-de-trabalho já era muitas vezes maior do que se estivesse no hospital. Ademais, o trabalho do médico na empresa já diferenciava-se como trabalho produtivo, distinto do trabalho médico fora da empresa que, do ponto de vista da produção capitalista, geralmente não pode ser assim considerado (Gonçalves, 1979).

Somente nos primeiros anos do século atual, com a definição de um conjunto de doenças como originadas do trabalho, a Medicina do Trabalho passou a ser tomada como um campo claramente diferenciado. Contudo, como cres- 
ceu sob a influência do unicausalismo, o objeto constituído privilegiou a atenção aos acidentes de trabalho e às doenças profissionais relacionadas com um agente nocivo específico encontrado em determinado ambiente de trabalho (Lauren, 1981; Mendes, 1980).

A teoria da causação múltipla, surgida em meados deste século, substitui o modelo da causa única pela rede causal, mas buscando, pragmaticamente, identificar os elos frágeis da corrente causal, para melhor controlar a doença, resultando numa abordagem também reducionista. A Medicina do Trabalho veio adotar essa nova abordagem, especialmente como foi delineada por Leavell \& Clark (1978) na tríade agente - hospedeiro - ambiente. Essa abordagem das doenças profissionais e o afastamento do universo das patologias em relação ao processo de trabalho, não reconhecendo a vinculação entre os perfis de morbi-mortalidade das classes subalternas e o trabalho nas fábricas, marcam todo o período de surgimento da Medicina do Trabalho (Sousa, 1989).

Embora venha a reconhecer mais tarde, ainda que parcialmente, a existência de doenças relacionadas com as condições de trabalho, bem como de outros processos mórbidos com frequiência ou gravidade maior entre os trabalhadores, os paradigmas originalmente firmados para as doenças profissionais marcaram indelevelmente a área (Abrasco, 1990).

Para Breilh (1989), o modelo de Leavell \& Clark reduz o elemento homem, ou hospedeiro, à sua dimensão animal, convertendo-o numa categoria natural, escondendo a sua inserção no sistema produtivo e a origem social do processo saúde-doença. $\mathrm{O}$ ambiente e o agente só estabeleceriam com o homem conexões externas, de onde se poderiam tirar conclusões de que, atuando com medidas de tipo ecológico sobre aqueles, é possível afastar a enfermidade do hospedeiro. Nesse modelo, o social é nomeado mas não aparece como um mecanismo explicativo. É afirmado - negado, assumido tão somente na condição de mito, diz Arouca (1976).

Segundo Laurell (1981), a própria categoria trabalho é tratada pelo pensamento clássico da Medicina de Trabalho como um problema ambiental, uma vez que o põe em contato com agentes químicos, físicos, biológicos ou psicológicos que causam no trabalhador aci- dentes ou enfermidades. Sousa (1989) destaca que, embora o agente e o ambiente de trabalho tenham papéis centrais na causação das doenças profissionais, não há como esconder as múltiplas conexões da causação que atingem o interior do próprio processo de trabalho. Tomando o exemplo do enunciado "a poeira da sílica é responsável pela silicose", o autor, admitindo-o lógico e clássico, critica a sua limitação por não explicitar que os cristais de sílica, para se apresentarem sob forma de partícula, necessitaram da intervenção do trabalho humano sobre a natureza, em condições dadas de exploração e sob uma dada tecnologia no processo produtivo. Embora seja difícil imaginar como, numa frase, o autor reuniria as variadas determinações envolvidas, é correta, ao nosso ver, a sua crítica de que a explicação causal não pode se resumir a um agente, quando envolve, em verdade, condições históricas em que os fatores são gerados e diz respeito a uma força de trabalho inserida socialmente.

Ao conceituar doença como um processo apenas biológico, a Medicina do Trabalho vai buscar sempre agentes-ambientes causais capazes de desencadear processos biológicos. Com isso, as doenças do trabalho são consideradas como desvios ou fatos inevitáveis no processo técnico de trabalho. Laurell (1981) afirma que, aceito esse ponto de vista, a luta entre trabalho e capital neste campo específico, cujos resultados em parte se evidenciam na legislação trabalhista, ficaria reduzida apenas a se tal ou qual trabalho causa enfermidade ou não.

A fixação de uma norma que reduz a causação aos agentes ambientais, cumpriria a função de tornar natural e inevitável o modo de produção a uma determinada maneira de organizar o trabalho, ao tempo que legaliza o risco que não pode ser afastado "por razões estritamente técnicas" (Laurell, 1981: Azevedo, 1990). Transgredida a norma por parte do agente-ambiente, caberia ainda ao corpo do hospedeiro, o trabalhador, o ônus da prova, ou seja, demonstrar que o agravo se deve à causação reconhecida como possível.

A inserção particular da Medicina do Trabalho na recuperação e reprodução da força-de-trabalho, além das circunstâncias sócio-históricas específicas que fizeram-na adotar da Clínica e da Epidemiologia os seus modelos causais, faz com que 
privilegie esses modelos por lhe permitirem normatizar/normalizar de modo mais direto a saúde do trabalhador.

Não se quer negar que a incorporação desses modelos causais e normas sanitárias específicas tenha, também, trazido, como observa Correia (1992), avanços na melhoria das condições e ambientes de trabalho, uma vez que serviram de base à proibição ou restrição do uso de muitas substâncias danosas à saúde. Entretanto, as limitações que repercutem na Medicina do Trabalho são, até hoje, evidentes.

Basta olharmos alguns dos principais livrostexto disponíveis (Waldron, 1989; Raffle et al., 1991; Harrington \& Gill,1992; Desoille et al., 1987; Sartorelli, 1981) para vermos como ainda persiste, na abordagem feita pela Medicina do Trabalho, o enfoque que privilegia a busca de um só agente, quase sempre prevalecendo, nesses tratados, a divisão entre agentes físicos, químicos e biológicos, o que faz inevitável lembrar dos livros de clínica de doenças infecciosas.

Observe-se que o surgimento do multicausalismo na Epidemiologia estava vinculado ao estudo das doenças crônico-degenerativas, que não poderiam ser explicados pelo paradigma unicausal (biologicista), o mesmo ocorrendo em relação a agravos crônico-degenerativos relacionados ao trabalho. Entretanto, a Medicina do Trabalho, cujos laços mais fortes são com a Clínica e não com a Epidemiologia, parece assimilar apenas parcialmente esse enfoque.

Deve-se registrar, contudo, como diz Gonçalves (1990), que o modelo de abordagem das doenças crônico-degenerativas também não se liberta da idéia de "Doenças causadas por" (um determinado agente biológico), nem rompe com a concepção de que o organismo é naturalmente normal, no sentido fisiológico do termo.

É de se ressaltar que o papel normativo específico atribuído à Medicina do Trabalho, com freqüência vinculado à reprodução da força de trabalho, a exemplo do estabelecimento de critérios de normalidade para seleção dos mais aptos para o trabalho bem como a sua vinculação pericial para aplicação de mecanismos de remuneração ("monetização") àqueles que tiveram sua saúde agravada pelo trabalho, reforçam, de modo especial, a adoção, cada vez maior, de um modelo normalizador centrado no indivíduo e na causa única.
Por outro lado, ainda que formule que parte do seu papel é buscar a adaptação do trabalho ao homem, a Medicina do Trabalho participa do papel inverso, em parceria com a Higiene do Trabalho, tomando o ambiente e o processo de trabalho como algo que pode até ser gerenciado, mas não pode ser transformado. Valendo-se de parâmetros que limitam a exposição àqueles fatores, os toma-os como normais, não se dando conta, ou não admitindo, das limitações postas pelo processo de trabalho ao gerenciamento ambiental, apresentado como elemento técnico, o que veremos adiante em relação às normas de exposição dos trabalhadores nas indústrias que manipulam substâncias químicas.

Berlinguer et al.(1990) ressaltam, entre as limitações da Higiene do Trabalho, o fato de ela ser diacrônica em relação ao processo de trabalho e à adoção das tecnologias. Os autores, analisando a questão das inovações tecnológicas, sistematizam quatro modelos de abordagem da segurança e higiene do trabalho: 1) Substituição do trabalhador: uma inovação é feita no processo produtivo, resultando, após um período que chamam de latência clínica, em doença, donde segue-se o benefício monetário para o doente e a sua substituição por outro trabalhador; 2) Inovação Tardia: ocorre a inovação e, após a latência clínica, ocorre a doença, seguindo-se, além do benefício monetário, o estudo empírico e científico, de onde surge pesquisa e normas que resultarão em mudança da tecnologia; 3) Prevenção Secundária: semelhante ao anterior, à exceção de que a normatização e pesquisa ocorre de modo mais imediato à doença; 4) Prevenção Programada: exige o conhecimento experimental antes do processo produtivo, que só se instala após se conhecer o impacto sobre os trabalhadores, a população e o ambiente, e após a fixação de norma baseada no experimento prévio, mas ocorrendo doença, dá-se o previsto na prevenção secundária.

Este último modelo, ressaltam os autores, exigiria mudanças no processo produtivo; nos métodos de indagação clínica da Epidemiologia; na clareza da explicitação diagnóstica; no grau de cultura a organização dos trabalhadores; na sensibilidade, eficiência e objetividade do poder público; na legislação; no nível de conhecimento científico e tecnológico; nas condições em 
que se organizam o mercado e a concorrência. Tudo isso implicaria, consideram aqueles autores, avaliar as inovações tecnológicas sob o ponto de vista das pessoas e do ambiente, e não apenas sob o ponto de vista do balanço financeiro e do mercado, como normalmente se faz.

A nosso ver, mesmo considerando que este quarto modelo higienista sistematizado por Berlinguer et al., ainda se encontra nos marcos da produção capitalista, e sua adoção implicaria mudanças tão significativas que é difícil supor a sua adoção, salvo em circunstâncias muitos especiais de pressão por parte dos expostos a risco e da maioria da sociedade.

Em países como o Brasil, onde o modelo econômico é capitalista dependente e o desenvolvimento industrial se dá pela absorção de pesadas tecnologias e dos riscos delas decorrentes, sem mecanismos que, pelo menos, tornem menos selvagem a prática empresarial, as conseqüências danosas à saúde são evidentes e esperadas, o que, somadas à grande disponibilidade de mão-de-obra desempregada, coloca-nos no mais anacrônico dos modelos descritos, o da mera substituição do trabalhador agravado.

\section{A NORMATIZAÇÃO/NORMALIZAÇÃO DA EXPOSIÇÃO AO RISCO}

Como vimos, ao acatar como inevitável o modo de produção e o processo de trabalho postos, a Medicina do Trabalho recorre, dentre outras medidas, à fixação de normas que limitem parcialmente a exposição aos agentes ambientais constituídos ou reunidos inevitavelmente na fábrica. Num só movimento, legaliza o risco e reconhece-o como inevitável, portanto, normal.

As normas de exposição ocupacional estão, em sua grande maioria, voltadas ao trabalho cujos principais fatores de risco são os agentes químicos. Mesmo para estes, são variados os tipos e denominações de norma, sistematizando Colacioppo (1989) cinco formulações: 1) Limites de Tolerância, ou Valores Limites de Tolerância; 2) Níveis Aceitáveis de Exposição; 3) Níveis de Exposição Permitidos; 4) Limites de Exposição; 5) Concentrações Máximas Aceitáveis. O primeiro tipo, bastante difundido, como veremos, não explicita bem o que significa tolerância, enquanto o segundo diz claramente que o que pretende controlar é a exposição e não o ambiente, tipo que se repete no terceiro, com uma denominação mais voltada à ação fiscalizadora de órgãos governamentais. O quarto tipo citado, Limites de Exposição, advem do propósito da OIT (Organização Internacional do Trabalho) de formular um objetivo misto de controlar a exposição a adequar o ambiente. $\mathrm{O}$ quinto tipo, destaca Colacioppo, traz uma proposta diferente dos demais, pois refere-se ao máximo valor de exposição em qualquer momento do dia de trabalho, não adotando, como nos outros casos, o uso de médias, sendo por isso, geralmente, mais protetor.

O tipo de norma de exposição mais usado em todo o mundo, como dissemos, segue o modelo do Limite de Tolerância, inclusive no Brasil, daí nosso interesse particular nele. O Informe Técnico número 601 da Organização Mundial da Saúde (OMS,1977) nomeia o Limite de Tolerância (LT) com a expressão "níveis admissíveis", norma quantitativa de higiene exprimida como concentração em função de uma média de tempo. Diz aquele informe que, para a definição desses valores, que estabelecem um nível de exposição que não pode resultar em risco significante de efeitos adversos à saúde, seriam necessários estudos toxicológicos preliminares, experimentos em animais e observações em seres humanos, destacadamente estudos epidemiológicos.

O primeiro valor-limite de exposição para um contaminante do ar foi o estabelecido para o monóxido de carbono, por Max Gruber, em 1883, que, após realizar experiências com animais, submeteu-se ele próprio à concentrações de 210 a 240 ppm durante dois dias, sem registrar sintomas ou sensação de desconforto (Paull, 1984; Cook, apud Arcuri \& Cardoso, 1991). Na década de 1920, nos Estados Unidos, começaram a ser elaboradas listas de padrões máximos de exposição e contaminantes do ar, geralmente baseados em experimentos animais relativos à toxicidade aguda. Estudos epidemiológicos de dose-resposta da exposição ocupacional ao asbesto, em 1938, e ao mercúrio, em 1940, permitiram a fixação de seus respectivos valores-limite de tolerância. Em 1960, na Inglaterra, estudos epidemiológicos possibilitaram a definição do 
limite de exposição à poeira de algodão no ar, responsável pela bissinose (Paull, 1984; Higgins, 1987; Nogueira,1973).

Assim como os critérios de classificação de doenças profissionais têm variado em função de circunstâncias sociais e históricas, os "níveis admissíveis" de exposição modificam-se enormemente de um para outro país, de uma para outra época. O informe da OMS há pouco referido, reconhece que essas variações "muitas vezes" se devem diretamente a fatores políticos e econômicos. Exemplifica que nos Estados Unidos os padrões são propostos com base em critérios de saúde, mas, quando da sua definição efetiva, leva-se em conta aspectos tecnológicos e econômicos. Na então URSS, dizia o informe, se reconhecia também que os fatores tecnológicos e econômicos influem nos níveis de exposição, contudos as normas eram definidas exclusivamente com base em critérios de salubridade (OMS,1977).

Para Holmberg \& Winel (1977), em um trabalho em que fazem uma revisão comparativa dos padrões usados na saúde ocupacional de 14 países, o conceito de 'standard' nessa área assume o princípio de que existe um nível-limite para os riscos existentes no ambiente de trabalho, onde é possível identificar um ponto de efeito-zero para cada substância ou fator. Contudo, observam os autores, para fatores como carcinógenos a alérgenos, ocorre grande debate sobre a suposta existência desse nível de efeito-zero ou se é possível determiná-to com razoável margem de segurança. Os autores analisam os padrões e seu processo de definição em países da Europa, Estados Unidos, Japão, México e a então União Soviética, confirmando que muito se diferenciam nos valores, nos critérios técnico-científicos, no fato de serem ou não elaborados por órgãos estatais, no seu status legal ou na abrangência da lista de substâncias ou fatores normatizados.

A mais conhecida lista de standards para exposição ocupacional no mundo é feita pela ACGIH (American Conference of Governmental Industrial Hygienists), associação americana não estatal de higienistas industriais. Foi iniciada em 1947, a partir de trabalhos originais de Warren Cook, de 1945 (Paull, 1984; Cook, 1992), e seus padrões, os Threshold Limit Values (TLV), que atualizam desde então, são o principal conjunto de normas utilizado pela Higiene Industrial americana, tendo se tornado também a base principal ou única das normas utilizadas no México, Japão, Inglaterra, Noruega, Finlândia, Dinamarca e muitos outros, inclusive o Brasil.

Desde 1970, existe nos Estados Unidos uma outra lista de padrões elaborada pela OSHA (Occupational Safety and Health Administration), órgão estatal vinculado ao Departamento de Trabalho. A OSHA foi criada e adotou a maioria dos TLV por ato específico do Congresso do seu país e em função disso o seu processo de estabelecimento de critérios, embora tido como mais criterioso que o da ACGIH, é mais lento e burocrático, uma vez que depende da apreciação do Poder Legislativo. Em razão dessa diferença entre os dois órgãos quanto ao rigor científico e agilidade, as duas listas continuam a apresentar grandes diferenças (Paull, 1984; Rappaport, 1993). Ademais, a relação entre a OSHA e outras agências federais americanas que atuam na área não é tranqüila, havendo competição e contradição entre elas, inclusive com o NIOSH (National Institute for Occupational Safety and Health), órgão estatal ligado ao Departamento de Saúde, Educação e Bem-estar (Robinson \& Paxman, 1991; Ziem \& Castleman, 1989).

Por outro lado, os padrões utilizados na Suécia, Alemanha e na ex-União Soviética são os que mais diferem dos estabelecidos pela ACGIH, em especial os da última, a começar da própria concepção prevencionista. Enquanto o TLV da ACGIH visa prevenir efeitos adversos à saúde da maioria dos trabalhadores no decorrer de toda sua vida laboral, excetuando aqueles particularmente sensíveis, com ênfase nos efeitos clínicos e bioquímicos, os MAC (Maximal Allowed Concentration) usados na ex-URSS não aceitam desvios do padrão fisiológico, visam proteger todos os trabalhadores, no curso de toda a sua vida ou da sua próxima geração, e enfatizam, os efeitos no comportamento e no sistema nervoso central (OMS, 1977; Rantanen et al., 1982) .

Holmberg e Winell (1977) fizeram comparações entre os padrões da OSHA e os soviéticos e mostraram que as maiores diferenças estão nos 'standards' para solventes orgânicos, verificando valores norte-americanos de até 95 vezes maior 
que o valor da URSS, o que consideram ser conseqüência da ênfase dada pela norma soviética aos distúrbios neuro-comportamentais. Para os autores, o processo de definição de padrões de exposição depende de fatores como (1) critério biológico escolhido e grau de exatidão do método usado para estabelecer o critério; (2) a evolução da tecnologia disponível e (3) as pressões pela qualidade do ambiente de trabalho, considerando eles que os dois primeiros são os que mais interferem.

Castleman \& Ziem (1988) destacaram outros fatores no processo de definição, dos padrões, ao publicarem, em 1988, a mais crítica avaliação dos TLVs da ACGIH. Estudaram o processo de definição do TLV de 104 substâncias, avaliando os documentos oficiais; as referências relativas a dados não publicados oriundos de empresas e que foram usados pela associação de higienistas; os posicionamentos adotados por empresas que influenciaram de diferentes modos na definição dos TLVs e ainda a sua relação com os membros da ACGIH.

Demonstraram os autores que, na grande maioria dos casos estudados, os padrões estavam baseados em poucas evidências científicas, por vezes sem a mínima revisão de literatura. Revelaram que membros do comitê da ACGIH, responsável pela definição dos padrões eram, simultaneamente, consultores de conglomerados industriais interessados; que a influência das empresas na definição dos valores se davam, com frequência, em dados não publicados e até relatos de experiência feitos por telefone; que era evidente que a interferência das empresas se dava por razões econômicas e não porque eram elas que detinham maior experiência com o produto; que o comitê dos TLVs não proporcionava a outros segmentos sociais a mesma oportunidade de participação. Castleman \& Ziem (1988) defenderam a necessidade de se constituir um comitê internacional de experts, sob os auspícios de uma organização internacional respeitada, com financiamento próprio, que pudesse revisar toda a documentação e a experiência existente nos diversos países, realizando estudos científicos que permitissem a confecção de uma lista de valores.

Consideram os autores ser fundamental que as partes financeiramente interessadas não tutelem mais o processo de definição dos pa- drões, que deve, por outro lado, ser aberto à sociedade, inclusive aos representantes dos trabalhadores expostos. Para Castleman a Ziem (1988), os valores-limite a serem estabelecidos servirão de parâmetro para a proteção da maioria dos trabalhadores e não para todos e opinam também que o conceito de exposição segura para todos os agentes químicos é inerentemente não científico. Consideram que tal processo deve ser científico, mas não se deve obscurecer que será sempre político, uma vez que trata-se de um grupo social (cientistas) decidindo o que é aceitável para outro grupo social (trabalhadores).

A repercussão do trabalho de Castleman e Ziem abriu uma intensa polêmica sobre a validade do TLV da ACGIH entre pesquisadores de diversos países. Aksoy (1988), da Turquia, destacado pesquisador dos agravos relacionados ao benzeno, diz que concorda inteiramente ser necessário um esforço internacional para desenvolver cientificamente e rever os TLV vigentes, num clima de abertura e sem manipulação de interesses. Djuric (1988), membro do Comitê do MAC da ex-Yugoslavia, diz que comparava antes o MAC da URSS e o TLV da ACGIH e atribuía essa grande diferença a aspectos metodológicos e ao fato do padrão soviético enfocar mais as repercussões neurológicas, considerando ainda que o padrão norte-americano era mais realista, fatores que motivavam que estes fossem adotados quase que integralmente, mostrando-se agora surpreso pelo fato de não terem base científica adequada.

Muir (1988), diretor de programa de saúde ocupacional de universidade do Canadá, diz que a fonte da deturpação dos TLV está no fato de que eles deixaram de ser usados como simples referência prática para ser usados na distinção do que é ou não condição segura do ambiente de trabalho. Duncan (1988), da Grã-Bretanha, contesta Castleman a Ziem, dizendo que nem sempre se dispõe de evidências científicas suficientes de que a definição de standard não deve ser feita apenas por cientistas e doutores, devendo-se acatar a contribuição dos diversos segmentos interessados. Argumenta este pesquisador, ademais, que os cientistas e doutores que trabalham para a indústria não são necessariamente corruptos e aqueles que são financiados por universidades, governos ou sin- 
dicatos não são necessariamente impecáveis; logo, defende a intensa cooperação entre eles como requisito para a elaboração de normas de exposição ocupacional.

Ahlberg (1989), representante do sindicato dos metalúrgicos no Comitê do TLV sueco, revelou-se chocado ante a informação da influência das indústrias na definição dos padrões da ACGIH que, para ele, teve a sua credibilidade atingida para sempre. Questiona: "quantos trabalhadores em todo o mundo adoeceram ou morreram?", posicionando-se que a associação americana deveria parar de publicar sua lista, pois "a falsa segurança que ela proporciona pode prejudicar mais que ajudar os trabalhadores", apoiando afinal, a proposta de criação de uma organização mundial independente para definição de normas de exposição ocupacional.

Herbert Stokinger (1988), toxicologista que presidia o Comitê do TLV há mais de 25 anos, reagiu agressivamente dizendo, em contraste com notórias evidências científicas, que nunca foram constatados efeitos sérios à saúde em trabalhadores expostos a substâncias nos níveis padronizados pela ACGIH e que isso é o que mais importa e não o processo como estes foram definidos: "a prova do pudim se faz ao comê-lo e não na sua preparação". Stokinger contesta a proposta de criação de um comitê internacional que definisse limites de exposição rigorosos e científicos, dizendo que muito já se tentou neste sentido no passado, sem qualquer sucesso. Em justificação ao fato de representantes industriais terem sido consultados e praticamente definido vários TLVs, usa a história do juiz que perguntou ao ladrão "Por que você rouba bancos?", ao que este respondeu "Porque é lá que está o dinheiro", argumentando o Presidente do Comitê que não há como definir padrões sem valer-se do auxílio dos que lidam com as substâncias e suas consequências à saúde humana.

Cox (1988), em nome da Associação das Indústrias Químicas, também defende que não há conflito de interesse em profissionais consultores ou empregados colaborarem com a sua experiência na definição dos TLVs e argumenta que qualquer parte interessada, seja representante da indústria, da academia ou dos trabalhadores, pode ter acesso à documentação durante este processo.
A polêmica resultante do trabalho de Castleman \& Ziem (1988) continuou repercutindo entre pesquisadores da área (Abrams, 1988; Djerassi, 1988; Dror, 1988; Elkins, 1988; Finklea,1988; Frank, 1988; Fraser, 1988; Lerman, 1988; Morton, 1988; Nordberg et al., 1988; Parmeggiani, 1988; Sass, 1988; Silbergeld, 1988; Tsuchiya, 1988; Woitowitz, 1988; Ahiberg, 1989; Frumkin, 1989; Sentes, 1989; Castleman \& Ziem, 1990; Coles, 1990), com a maioria dos autores colocando-se numa posição crítica à ACGIH.

No debate relativo à norma de exposição ocupacional, quase todos os autores defendem a sua necessidade como instrumento de proteção à saúde e segurança dos trabalhadores expostos. Robinson (1989) reconhece que essas normas estabelecidas oferecem a descrição de condições que definem a qualidade ambiental ou ocupacional, oferecendo as medidas para a proteção da saúde e segurança do trabalhador médio. O caso especial, tal como a pessoa hipersensitiva ou aquela geneticamente predisposta ao agravo por determinado fator, não é normalmente protegido. Pitcher (1990) apresenta critérios de fixação de padrões em que o principal critério para a definição da norma de exposição é a disponibilidade de tecnologia disponível para a sua implementação, tanto do ponto de vista da produção, levando-se em conta o custo-benefício, quanto do controle ambiental. Em termos práticos, vê-se que a saúde não é posta como alvo central desse processo.

Roach \& Rappaport (1990) retomam a discussão sobre o alcance da proteção dos expostos, apresentando um estudo que foi outro duro golpe na ACGIH. Os autores analisam as referências bibliográficas das listas de padrões da associação emitidas em 1976 e 1986, selecionando as relativas a observações de exposição humana e de experiência industrial, comparando-os, então, com a literatura científica, muitas vezes conhecidas há várias décadas, demonstrando que, para a maioria dos TLVs analisados, havia relatos de efeitos adversos em níveis iguais ou inferiores ao valor-limite. O estudo também constatou uma alta correlação entre os valores já praticados na indústria e aqueles que vieram a ser normatizados pela ACGIH, evidenciando, na prática, um processo ainda mais distanciado das necessidades 
de saúde. Para esses autores, os TLVs podem até ser considerados guias de ação fáceis de ser acatados pela indústria, mas, seguramente, não são limites de tolerência.

Embora os TLVs ainda continuem sendo uma referência técnica importante em todo o mundo e o Comitê venha tentando fazer modificações (Rappaport, 1993), as críticas contidas nos estudos de Castleman \& Ziem (1988) e Roach \& Rappaport (1990) resultaram em duros golpes em sua credibilidade e, com isso, o conceito de exposição segura. A suspeita que tem pairado é que, quando se diz que a norma deve ser tão factível quanto possível, o que se quer é que a norma seja não apenas aquela aceitável do ponto de vista da viabilidade econômica, como também aquela que já se pratica nas empresas. Ou seja, o que se busca na norma é a manutenção dos níveis de exposição vigentes.

Tarlau (1990), criticando a Higiene Industrial americana, diz que os limites de exposição são teoricamente úteis aos trabalhadores quando as normas e os órgãos de controle têm os números corretos, mas o autor acha que a Higiene usualmente não os têm. Diz ele que "limites de exposição nos permitem declarar, de um modo pseudo-científico difícil de ser refutado pelos trabalhadores, que as exposições são seguras, apesar de ninguém realmente saber se elas são ou não". O mesmo autor cita também os trabalhos de Castleman \& Ziem como atestado de que diversos limites fixados pela ACGIH não têm valores de nenhum modo confiáveis, afirmando ainda que, para a vasta maioria dos produtos químicos, temos poucos ou nenhum dado sobre toxicidade crônica.

Defende Tarlau a abolição de todos os limites pela Higiene, dizendo que continuar a usá-los é dar-lhes credibilidade. Propõe o higienista, ligado ao Departamente de Saúde do estado norte-americano de New Jersey, uma prática da Higiene "à moda antiga", observando e ouvindo os trabalhadores e o processo de trabalho, anotando e documentando suas queixas e sintomas, preparando bons relatórios de investigação, que devem ser remetidos para o empregador e para os empregados ou seus representantes, deixando o higienista de gastar a maior parte do tempo olhando para instrumentos e dosímetros ou anotando números. Em sua opinião, essa seria a forma de livrar-se do dilema posto pelos limites: nada pode ser feito "sem prova de exposição além dos limites" e ninguém pode provar tal exposição além dos limites porque estes foram estabelecidos em valores altos.

Embora o higienista há pouco citado formule com precisão as críticas aos padrões de exposição, a possibilidade prática e os benefícios da sua proposta, abolição imediata dos limites, devem, a nosso ver, ser analisados nos marcos da Higiene Industrial americana.

\section{O USO DE PADRÕES DE EXPOSIÇÃO NO BRASIL}

Em nosso país, a Medicina do Trabalho também chegou com a indústria, que começou a implantar-se aqui apenas no final do século passado. O papel do Estado naquele período e, em especial, no início do século XX, no controle das condições de trabalho, voltava-se para a promoção de campanhas sanitárias nos portos visando a erradicação da malária e da febre amarela, que provocavam milhares de mortes entre brasileiros e impediam a vinda de imigrantes imprescindíveis como operários da nascente indústria.

A legislação brasileira de proteção à saúde no trabalho desenvolveu-se, entre diversos fatores, como uma necessidade de expansão da própria indústria, mas também pela pressão dos trabalhadores que exigiam que os protegessem ante os variados fatores de risco a que estavam expostos (Abrasco, 1990; Diesat 1989).

A primeira proteção legal no Brasil relativa aos acidentes e doenças de trabalho foi um decreto de 1919, que era muito limitado porque só previa a indenização dos acidentes no local de trabalho e das doenças profissionais, excluindo as mesopatias e outros agravos relacionados ao trabalho, além de exigir que, em caso de acidente, este representasse causa única da incapacidade laborativa (Ribeiro \& Lacaz, 1984). No período do Estado Novo, de 1930 à metade da Ãécada seguinte, ampliou-se o arcabouço institucional relacionado á saúde no trabalho. As lutas dos trabalhadores e o caráter nacional-populista do regime de então resultaram na expansão da legislação acidentária, na criação do adicional ao 
salário por insalubridade na indústria e foi introduzida a noção de limite de exposição aos agentes nocivos (Possas, 1989; Diesat, 1989; Ribeiro \& Lacaz, 1984).

A introdução do limite de tolerância (LT) no país, em 1978, representou uma alteração significativa na norma vigente que, embora previsse tais limites, não os tinha fixado. Prevaleciam, por isso, critérios qualitativos para definição do ambiente insalubre e argumentava-se que tal procedimento seria modificado quando os órgãos competentes passassem a ter os recursos técnicos e materiais necessários. Como a fixação de valores para os LT naquele ano se deu antes que a carência de recursos tivesse sido solucionada, Ribeiro \& Lacaz (1984) consideram ter havido um retrocesso na classificação dos ambientes insalubres, pois tornava-os, na prática, ambientes aceitáveis, já que era impraticável realizar a quantificação definida.

Mas o maior erro na fixação dos limites de tolerância no Brasil (Norma Regulamentadora ${ }^{\circ}$ 15 da Portaria $\mathrm{MTb}^{\circ}{ }^{\circ}$ 3.214/78) não foi, a nosso ver, a decisão de fixá-los e sim tê-los, em grande parte, importado da lista da ACGIH sem que tivessem sido, pelo menos, feitos estudos sobre a sua aplicação nas condições de nosso país e de seus trabalhadores. A adaptação dos TLV para o Brasil enfocou apenas a diferença de jornada semanal de trabalho: a americana é de 40 horas e a brasileira era de 48 horas. Desse modo, por exemplo, na exposição ao benzeno, o TLV de 10 ppm (partes por milhão) passou a ser o LT brasileiro de 8 ppm.

Em países desenvolvidos, apesar dos LT serem freqüentemente definidos sem qualquer sustentação científica, a luta organizada dos trabalhadores consegue algumas vezes obrigar a redução dos valores-limite considerados mais permissivos. No Brasil, contudo, os sindicatos de trabalhadores não têm obtido grandes resultados nessa área, mesmo sabendo-se que a maioria dos LT não tem real base científica e que não foram feitos estudos específicos para as condições aqui existentes, copiando-se valores de outros países sem qualquer crítica ou, no máximo, fazendo-se pequenas adaptações (Possas, 1989).

Além disso, nossa legislação tem problemas outros como o fato de que apenas 27 doenças profissionais ou do trabalho são reconhecidas para fins de indenização; o não reconhecimento da exposição a agentes interatuantes; e, em caso de insalubridade constatada, é vedada a percepção de adicional cumulativo, só valendo o grau mais elevado.

A falta de controle regular da exposição ocupacional é tamanha no Brasil, que, mesmo em casos como o da exposição ao benzeno, repercute pouco aqui a polêmica relativa aos LT existente em outros países, inclusive aquela existente em países de onde foram importados os "nossos" padrões. Tal se dá, obviamente, muito mais porque os valores vigentes são aqui seguidamente descumpridos, do que pela consciência de que têm fragilidade científica.

Essa realidade permite-nos constatar que a Higiene Industrial em nosso país ainda é mantida em estágio inicial e a proposta de abolição dos padrões defendida por Tarlau (1990) a sua substituição por práticas mais elaboradas de Higiene poderia implicar agravamento do quadro atual, mesmo considerando a precariedade das normas e o papel que elas representam na normalização do ambiente. Seria desconhecer, por exemplo, que grande pane das avaliações ambientais que deveriam ser feitas regularmente ainda não têm sua metodologia definida ou exigem equipamentos que poucas empresas possuem ou dominam.

Além disso, à não realização de avaliações ambientais, está associado outro tipo de distorção na indústria no Brasil: a utilização de exames biológicos de rotina nos trabalhadores para monitorar os níveis de exposição. Os indicadores biológicos, a exemplo da dosagem de fenol urinário na suspeita de exposição acentuada ao benzeno, deveriam apenas auxiliar na adoção de medidas de proteção à saúde coletiva a não ser um meio de transformar o trabalhador em "cobaia", ou amostrador do ambiente de trabalho, como diz Buschinelli (1989). Essa distorção poderia aumentar se se abolissem os LT.

Embora concordemos com as formulações de Tarlau (1990) em relação à necessidade do higienista observar mais e ouvir os trabalhadores e o processo de trabalho, tal como Arcuri e Cardoso (1991), entendemos que, ao invés de abolir os limites, devamos defender que sejam utilizados enquanto guias e se realize uma ampla revisão 
de todos os valores hoje pratica dos no país, com base em estudos científicos e transparentes, ao que se devam seguir reavaliações periódicas.

\section{RESUMO}

\section{VASCONCELOS F. D. Uma Visão Crítica do Uso de Padrões de Exposição na Vigilância da Saúde do Trabalhador. Cad. Saúde Públ. Rio de Janeiro, 11 (4): 588-599, out/dez, 1995.}

Os Limites de Exposição ocupacional a agentes químicos utilizados na indústria são analisados no contexto da aplicação reducionista que a Medicina do Trabalho faz dos conceitos de causa e norma. São discutidas algumas das lacunas técnico-científicas desses Limites de Exposição, inclusive daqueles utilizados no Brasil, bem como seu uso como instrumentos de normalização do ambiente de trabalho.

Palavras-chave: Medicina do Trabalho; Exposição Ocupacional; Agente Químico; Limite de Tolerância; Vigilância em Saúde

\section{REFERÊNCIAS BIBLIOGRÁFICAS}

ABRAMS, H. K., 1988. Credibility in the TLV Process. American Journal of Industrial Medicine; 13: 609-610.

ABRASCO, 1990. (Associação Brasileira de PósGraduação em Saúde Coletiva) Saúde e Trabalho: Desafios para uma Política, Documento Institucional.

AHLBERG, R., 1989. Re: Corporate influence on threshold limit values. American Journal of Industrial Medicine, 15: 233

AKSOY, M., 1988. Letter. American Journal of Industrial Medicine, 14: 735.

ARCURI, A. S. A. \& CARDOSO, L. M. N., 1991. Limites de tolerância? Revista Brasileira de Saúde Ocupacional, 19: 99-105.

AROUCA, A. S. S., 1976. A história natural das doenças. Saúde em Debate, 1: 15-19.

AZEVEDO, F. A., 1990. Breves Referências aos Aspectos Toxicológicos do Benzeno, Salvador: Fundação José Silveira.

BERLINGUER, G.; CONTI, P. \& SMARGIASSE, A., 1990. Modelli Preventivi nell' Igiene del Lavoro. $53^{\circ}$ Congresso Nazionale della Società Di Medicina
Del Lavoro e Igiene Industriale, Stressa, 10-13 ottobre. (Mimeo.)

BREILH, J., 1989. Epidemiología, Economía, Medicina y Política. México: Fontamara.

BUSCHINELLI, J. T. P., 1989. Conceitos, indicações e utilização de indicadores biológicos. In: Programa de Saúde do Trabalhador - A Experiência da Zona Norte: Uma Alternativa em Saúde Pública (Costa D. F. \& Carmo, J. C. \& Settimi, M. M. \& Santos, U. P., orgs.), pp. 299-348, São Paulo: Hucitec.

CASTLEMAN, B. I. \& ZIEM, G. E., 1988. Corporate influence on threshold limit values. American Journal of Industrial Medicine, 13: 531-559.

1990. Letter to the editors. Archives of Environmental Health, 128: 250.

COLACIOPPO, S., 1989. Limites de exposição. In: Tópicos de Saúde do Trabalhador (F. M. Fisher; J. R. Gomes \& S. Colacioppo, org.), pp. 99-132, São Paulo: Hucitec.

COLES, G. V., 1990. Letter to the Editors. Archives Environmental Health, 128: 248-250.

COOK, W. A., 1992. Criteria for Occupational Exposure Limits by Selected Countries. American Industrial Hygiene Association Journal., 53: 395-397.

CORREIA, M. C. P., 1992. A Questão do Diagnóstico dos Casos de Doença Ocupacional no Estado da Bahia a Partir do Ano de 1988. Tese de Mestrado, Salvador: Universidade Federal da Bahia.

COX, G. V., 1988. Threshold limit values: a balanced report. American Journal of Industrial Medicine, 14: 233-234.

DESOILLE, H.; SCHERRER, J. \& TRUHAUT, J., 1987. Précis de Médecine du Travail. 5' ed., Paris: Masson.

DIESAT (Departamento Intersindical de Estudos e Pesquisas de Saúde e dos Ambientes de Trabalho), 1989. Insalubridade: Morte Lenta no Trabalho. São Paulo: Oboré

DJERASSI, L., 1988. Time to reconsider TLVs. American Journal of Industrial Medicine, 13: 611-612.

DJURIC, D., 1988. Coments on the article by Castleman and Ziem. American Journal of Industrial Medicine, 13: 613-614.

DUNCAN K.P., 1988. Standard setting. American Journal of Industrial Medicine, 13: 619-620.

DROR, K., 1988. TLVs - A Personal Opinion. American Journal of Industrial Medicine, 13: 617-618.

ELKINS, H.B., 1988. Response to "corporate influence on threshold limit values" [Letter]. American Journal of Industrial Medicine, 14: 737-740.

ENGELS, F., 1985. A Situação da Classe Trabalhadora na Inglaterra, São Paulo: Global. 
FINKLEA, J., 1988. Threshold limit values: A Timely look. American Journal of Industrial Medicine, 14: 211-212.

FRANK, A. L., 1988. Corporate influence on threshold limit values by castleman and Ziem [Letter]. American Journal of Industrial Medicine, 13: 607-608.

FRASER, D. A., 1988. Re: corporate influence onthreshold limit values. American Journal of Industrial Medicine, 15: 235-236.

FRUMKIN, H., 1989. Standard setting, science, and politics. American Journal of Industrial Medicine, 15: 347-350.

GONÇALVES, R. B. M., 1979. Medicina a História - Raízes do Trabalho Médico. Tese de Mestrado, São Paulo: Universidade de São Paulo.

1990. Reflexão sobre a articulação entre a investigação epidemiológica e a prática médica a propósito das doenças crônicas degenetativas. In: Epidemiologia - Teoria e Objeto (D. C. Costa, org.), pp. 39-86, São Paulo: Hucitec/Rio de Janeiro: Abrasco.

HARRINGTON, J.M. \& Gill, F. S., 1992. Occupational Health, 3rd. ed., London: Oxford.

HIGGINS, I. T., 1987. Epidemiology in occupational health policy. In: Epidemiology Health Policy ( $S$. Levine \& Lilienfeld, A. org.) pp. 157-176, New York: Tavistock Publications.

HOLMBERG, B. \& Winell, M., 1977. Occupational health standards: an international comparation. Scandinavian Journal of Work, Environment \& Health, 3: 1-15.

LAURELL, A. C., 1981. Processo de trabalho e saúde. Saúde em Debate, 11: 8-22.

LEAVELL, H. R. \& Clark, E. G., 1978. Medicina Preventiva. São Paulo: McGraw Hill do Brasil.

LERMAN, Y., 1988. Quis custodiet ipsos custodes (Juvenal, 98 A. D.) (letter). American Journal of Industrial Medicine, 13: 621-622.

MENDES, R., 1980. Medicina do Trabalho - Doenças Profissionais. São Paulo: Sarvier.

MORTON, W. E., 1988. The nature and significance of the corporate influence on threshold limit values. American Journal of Industrial Medicine, 14: 721-723.

MUIR, D. C. F., 1988. TLVs - what now? (Letter) American Journal of Industrial Medicine, 13: 605-606.

NOGUEIRA, D. P., 1973. Bissinose no município da capital do estado de São Paulo, Brasil. Revista Saúde Pública, 7: 251-272.

NORDBERG, G. F.; FROSTLING, H.; LUNDBERG, P. \& WESTERHOLM, P., 1988. Swedish occupational exposure limits: developments in scientific evaluation and documentation. American Journal of Industrial Medicine 14: 217-221

OMS (Organización Mundial de la Salud), 1977. Criterios Utilizados para Establecer Níveles Admisibles de Exposición Profesional a los Agentes Nocivos. Ginebra: OMS. (Serie de Informes Técnicos, 601).

PARMEGGIANI, L., 1988. An international viewpoint on exposure limits. American Journal of Industrial Medicine, 14: 213-214.

PAULL, J. M., 1984. The origin and basis of threshold limit values. American Journal of Industrial Medicine, 5: 227-238.

PITCHER, M., 1990. Standard setting: a political process. American Journal of Industrial Medicine, 17: 255-259.

POSSAS, C. A., 1989. Epidemiologia a Sociedade: Heterogeneidade Estrutural e Saúde no Brasil. São Paulo: Hucitec.

RAFFLE, P. A. B., LEE, W. R.; MCCALLUM, R. I. \& MURRAY, R., 1991. Hunter's Diseases of Occupations. London: Edward Arnold.

RAMAZZINI, B., 1988. As Doenças dos Trabalhadores. São Paulo: Fundacentro.

RANTANEN, J.; AITIO, A.; HEMMINKI, K; JARVISALO, J. LINDSTROM, K; TOSSAVAINEN, A. \& VAINIO, M, 1982. Exposure limits and medical surveillance in occupational health. American Journal of Industrial Medicine, 3: 363-371.

RAPPAPORT, S. M., 1993. Threshold limit value, permissible exposure limits, and feasibility: the bases for exposure limit in the United States. American Journal of Industrial Medicine, 23: 683-694.

RIBEIRO, H. P. \& LACAZ, F., 1984. De que Adoecem e Morrem os Trabalhadores. São Paulo: Diesat.

RITCHTER, E. D., 1988. On "corporate influence on threshold limit values" by Castleman and Ziem. American Journal of Industrial Medicine, 14: 365-368.

ROACH, S. A. \& RAPPAPORT, S. M., 1990. But they are not thresholds: a critical analysis of the documentation of threshold limit values. American Journal of Industrial Medicine, 17: 727-753.

ROBINSON, A. E., 1989. Standard setting and protection of human health and safety. American Journal of Industrial Medicine, 15: 213-231.

ROBINSON, J. C. \& PAXMAN, D. G., 1991. Public health and the law. American Journal of Public Health, 81: 775-780.

SARTORELLI, E., 1981. Tratatto di Medicina del Gavoro. Pandova: Piccim Editore. 
SASS, R., 1988. What's in a name? The occupational hygienist's problem with threshold limit values. American Journal of Industrial Medicine, 14: 355-363.

SENTES, R., 1989. Occupational exposure standards in Canada: From ACGIH to American Journal of Industrial Medicine, 16: 719-722.

SILBERGELD, E. K., 1988. Reflection on the problem of reliability in occupational and environmental toxicology. American Journal of Industrial Medicine, 13: 601-603.

SOUSA, R. P., 1989. Saúde do trabalhador: em busca de um paradigma. Saúde em Debate, 11: 50-52.

STOKINGER, H. E., 1988. Threshold limit values: any alternative? American Journal of Industrial Medicine, 14: 231-232.

TARLAU, E. S., 1990. Higiene Industrial sem Limites, pp.7, São Paulo: Fundacentro (Mimeo.)
TSUCHIYA, K., 1988. Significance and use of threshold limit values with reference to "corporate influence on threshold limit values" by Castleman and Ziem. American Journal of Industrial Medicine, 14: 215-216.

WALDRON, H. A., 1989. Occupational Health Practice. 3rd. ed., London: Butterworths.

WOITOWITZ, H. J.,1988. Maximum concentrations at the workplace in the Federal Republic of Germany. American Journal of Industrial Medicine, 14: 223-229.

ZIEM, G. E. \& CASTLEMAN, B. I., 1989. Threshold limit values: historical perspectives and current practice. Journal of Occupational Medicine, 31: 910-918. 